\title{
Statin effect on thrombin inhibitor effectiveness during percutaneous coronary intervention: a post-hoc analysis from the ISAR-REACT 3 trial
}

\author{
Ahmed A. Khattab - Gjin Ndrepepa - Stefanie Schulz • Franz-Josef Neumann • \\ Julinda Mehilli · Heinz Joachim Büttner · Jürgen Pache • Melchior Seyfarth • \\ Josef Dirschinger $\cdot$ Adnan Kastrati $\cdot$ Peter B. Berger $\cdot$ Albert Schömig $\cdot$ Gert Richardt
}

Received: 14 September 2009/ Accepted: 26 January 2011/Published online: 11 February 2011

(C) Springer-Verlag 2011

\begin{abstract}
Objective To determine whether statin therapy influences the efficacy of thrombin inhibitor bivalirudin or unfractionated heparin (UFH) during PCI.

Setting and patients The post-hoc analysis of the ISARREACT 3 Trial included 4,570 patients: 3,106 patients were on statin therapy and 1,464 patients were not on statin therapy at the time of PCI procedure.

Main outcome measures The primary outcome of this analysis was the 30-day composite of death, myocardial infarction, target vessel revascularization (TVR) or major bleeding.

Results The primary outcome occurred in $7.9 \%$ patients $(n=246)$ in the statin group versus $9.8 \%(n=143)$ in the non-statin group $(P=0.036)$. There was an interaction in
\end{abstract}

\section{A. A. Khattab - G. Richardt}

Herz-Kreislauf-Zentrum, Segeberger Kliniken GmbH,

Bad Segeberg, Germany

G. Ndrepepa - S. Schulz - J. Mehilli - J. Pache - M. Seyfarth ·

A. Kastrati - A. Schömig

Deutsches Herzzentrum, Technische Universität,

Munich, Germany

F.-J. Neumann · H. J. Büttner

Herzzentrum, Bad Krozingen, Germany

J. Dirschinger · A. Schömig

Medizinische Klinik rechts der Isar,

Technische Universität, Munich, Germany

P. B. Berger

Geisinger Medical Center, Danville, USA

A. A. Khattab $(\bowtie)$

Cardiology Department, University Hospital,

3010 Bern, Switzerland

e-mail: ahmed.khattab@insel.ch univariate $(P=0.028)$ and multivariable $(P=0.026)$ analysis between pre-PCI statin therapy and the type of antithrombotic therapy regarding myocardial infarction. In the statin group, bivalirudin significantly reduced the incidence of major bleeding (2.6 vs. $4.3 \%, P=0.013$ ) with no significant difference in the incidence of myocardial infarction ( 4.9 vs. $5.2 \% ; P=0.73$ ) compared with UFH. In the non-statin group, bivalirudin was inferior to UFH regarding the incidence of myocardial infarction (7.1 vs. $4.1 \%, P=0.013$ ), yet major bleeding remained lower among bivalirudin-treated patients $(4.0$ vs. 5.2\%, $P=0.25$ ).

Conclusion This post-hoc analysis suggests the existence of an interaction between statin therapy before PCI and antithrombotic therapy during PCI. Patients receiving bivalirudin therapy at the time of PCI showed less periprocedural myocardial infarction when on pre-PCI statin therapy which has to be investigated in further studies.

Keywords Antithrombotics - Statins - Heparin · Bivalirudin · Stents

\section{Introduction}

Both ischemic and bleeding complications of percutaneous coronary interventions (PCI) influence 1-year mortality in patients undergoing PCI [1]. Accordingly, several newer antithrombotic agents have been compared with unfractionated heparin (UFH) in an attempt to reduce these adverse clinical events. Bivalirudin, a direct thrombin inhibitor, has been shown to significantly reduce bleeding in a wide clinical spectrum of coronary artery disease patients undergoing PCI compared to UFH, with or without adjunctive glycoprotein IIb/IIIa inhibitor adminstration 
[2-5]. Nevertheless, there has been a trend toward more frequent ischemic complications-mainly procedural myocardial infarction-with bivalirudin monotherapy, independent of clinical syndrome acuity, although greater, in some studies, in patients with acute coronary syndromes not treated with a thienopyridine [6]. Moreover, among patients treated by primary PCI for acute myocardial infarction, there was an increased frequency of acute stent thrombosis in the $24 \mathrm{~h}$ following the PCI procedure, however, the reinfarction rates were similar between bivalirudin and heparin plus glycoprotein IIb/IIIa inhibitor [4]. These apparently different effects of UFH and bivalirudin on the risk of myocardial infarction and bleeding have produced a significant reduction in net clinical outcomes with bivalirudin (the sum of ischemic and bleeding events) [2-4]. However, in the Intracoronary Stenting and Antithrombotic Regimen: Rapid Early Action for Coronary Treatment 3 (ISAR-REACT 3) Trial in which only biomarker negative patients were enrolled, the net clinical outcomes were similar with the two antithrombins, although bivalirudin did also reduce measures of bleeding compared to heparin alone [5].

The 3-hydroxy-3-methylglutaryl coenzyme A (HMG$\mathrm{CoA})$ reductase inhibitors or statins are a cornerstone therapy in the primary and secondary prevention strategies of coronary artery disease. It has recently been suggested that statins may reduce procedural myocardial infarction following PCI [7-10]. Their positive influence is hypothesized to result from not only lipid lowering but also other, non-lipid lowering (pleiotropic) effects, including antiinflammatory, antithrombotic and antiproliferative effects [11-15]. Therefore, an interaction with antithrombotic agents given during PCI is plausible in patients on statins.

In this study, a post-hoc analysis of the ISAR-REACT 3 trial, we sought to: (1) investigate the impact of pre-PCI statin therapy on the 30-day clinical outcome of patients enrolled in ISAR-REACT 3, and (2) to determine whether there is an interaction between pre-PCI statin therapy and antithrombotic agents (bivalirudin or UFH) in terms of ischemic events within 30 days, and in-hospital major bleeding.

\section{Methods}

The Intracoronary Stenting and Antithrombotic Regimen: Rapid Early Action for Coronary Treatment 3 (ISARREACT 3) trial included 4,570 biomarker negative patients with coronary artery disease in whom PCI was planned enrolled between September 2005 and January 2008. Details of the trial design, patient eligibility and laboratory measurements have been reported before [5]. In brief, all patients were pretreated with $325-500 \mathrm{mg}$ aspirin and
$600 \mathrm{mg}$ of loading dose of clopidogrel at least $2 \mathrm{~h}$ before the PCI procedure. Before the guide wire had crossed the lesion, patients were randomized to receive a $0.75 \mathrm{mg} / \mathrm{kg}$ bolus of bivalirudin followed by an infusion of $1.75 \mathrm{mg} / \mathrm{kg} / \mathrm{h}$ for the duration of procedure (bivalirudin group; $n=2,289$ patients) or $140 \mathrm{U} / \mathrm{kg}$ bolus of UFH followed by placebo infusion for the duration of the procedure (heparin group; $n=2,281$ patients). Double blinding was achieved by use of identically appearing vials in both study groups. Post-procedural therapy included daily aspirin, 80-325 mg indefinitely, clopidogrel, 75-150 mg/day until discharge but no longer than 3 days followed by $75 \mathrm{mg} /$ day for at least 1 month (bare-metal stents) or at least 6 months (drug-eluting stents) and other cardiac medications prescribed by the patient's physician. Electrocardiographic examinations and laboratory measurements including cardiac enzymes, hemoglobin and platelet count were performed every $8 \mathrm{~h}$ for the first $24 \mathrm{~h}$ after the PCI procedure and daily, until discharge.

The primary outcome of this post-hoc analysis was the combined incidence of death from any cause, myocardial infarction, urgent target vessel revascularization (coronary bypass surgery or PCI) due to myocardial ischemia within 30 days after randomization, or major bleeding during the index hospitalization (the composite quadruple endpoint) in patients on statins at time of randomization (statin group) and those not on statins (non-statin group) treated by bivalirudin or UFH. The definition of major bleeding used was the same as was used in the Randomized Evaluation in PCI Linking Angiomax to Reduced Clinical Events (REPLACE-2) trial [2]: intracranial, intraocular, or retroperitoneal hemorrhage, clinically overt blood loss resulting in a decrease in hemoglobin of more than $3 \mathrm{~g} / \mathrm{dl}$, any decrease in hemoglobin of more than $4 \mathrm{~g} / \mathrm{dl}$, or transfusion of 2 or more units of packed red blood cells or whole blood. The definition of myocardial infarction included the development of pathologic Q waves $(\geq 30 \mathrm{~ms}$ in duration and $\geq 0.1 \mathrm{mV}$ in depth) in $\geq 2$ contiguous precordial leads or $\geq 2$ adjacent limb leads, or elevation of creatine kinase (CK) MB isoenzyme (or total CK if CKMB not available) $\geq 2$ times the upper limit of normal. A phone interview was performed 30 days after the index PCI. Patients with cardiac complaints within the 30-day interval underwent a complete clinical, electrocardiographic, and laboratory evaluation.

The data are presented as mean $\pm \mathrm{SD}$ or percentages. Categorical data were compared with the Chi-squared test, or Fisher's exact test when expected cell values were $<5$. Continuous data were compared with two-tailed unpaired $t$ test. An interaction test between the type of antithrombotic therapy (bivalirudin or UFH) and statin use at the time of enrollment regarding the clinical outcome was performed. Multivariable analysis (the Cox proportional 
hazards model) was used to identify independent risk factors associated with 30-day myocardial infarction. Variables entered into the model were age, sex, statin therapy at randomization, diabetes mellitus, arterial hypertension, smoking, hypercholesterolemia, unstable angina, multivessel disease, prior myocardial infarction, antithrombotic agent and statin-antithrombotic agent interaction. Analysis was performed with the S-plus statistical package (S-PLUS, Insightful Corp, Seattle, Wash). A probability value $<0.05$ was considered to indicate statistical significance.

\section{Results}

The study included 4,570 patients: at the time of randomization and the index PCI procedure, 3,106 patients were on statins $(1,555$ patients randomized to bivalirudin and 1,551 patients randomized to UFH) and 1,464 patients were not (734 patients randomized to bivalirudin and 730 patients randomized to UFH). The baseline clinical characteristics of patients on and not on statins are shown in Table 1. Patients in the statin group had more adverse cardiovascular risk factors than patients in the non-statin group. Table 2 shows the angiographic and procedural data for all patients for each lesion treated. Table 3 shows main concomitant drug therapy recorded at admission.

The composite quadruple endpoint occurred less frequently in the statin group than the non-statin group (7.9 vs. $9.8 \%, P=0.036$ ). There were no significant differences in the individual components of the primary outcome; a trend toward a lower incidence of major bleeding among patients of the statin group was observed (3.4 vs. $4.6 \%, P=0.062)$. There was an interaction of borderline significance $(P=0.05)$ between statin use and antithrombotic agent regarding the primary outcome which became significant $(P=0.024)$ regarding the composite of death, myocardial infarction or urgent target vessel revascularization. For individual components of the composite outcome, there was an interaction $(P=0.028)$ between statin therapy and antithrombotic agent regarding the incidence of myocardial infarction. The clinical outcomes of statin and non-statin groups are shown in Table 4.

As a result of the observed interaction(s), the primary outcome and its individual components were separately investigated according to bivalirudin or heparin in the statin and non-statin groups. The results are shown in Table 5. It can be seen in the statin group that bivalirudin therapy resulted in significantly less major bleeding (2.6 vs. $4.3 \%, P=0.013$ ) with no significant difference in the
Table 1 Baseline characteristics of the study population
Data are mean $\pm \mathrm{SD}$ or number of patients (with percents in parentheses)

\begin{tabular}{|c|c|c|c|}
\hline Characteristic & $\begin{array}{l}\text { On statins } \\
(n=3,106)\end{array}$ & $\begin{array}{l}\text { Not on statins } \\
(n=1,464)\end{array}$ & $P$ value \\
\hline Study treatment group & & & 0.964 \\
\hline Bivalirudin & $1,555(50.1)$ & $734(50.1)$ & \\
\hline Unfractionated heparin & $1,551(49.9)$ & $730(49.9)$ & \\
\hline Age (years) & $67.2 \pm 10.4$ & $66.7 \pm 9.7$ & 0.106 \\
\hline Women-no. (\%) & $667(21.5)$ & $408(27.9)$ & $<0.001$ \\
\hline Diabetes-no. (\%) & $895(28.8)$ & $359(24.5)$ & 0.002 \\
\hline Insulin-treated-no. $(\%)$ & $270(8.7)$ & $97(6.6)$ & 0.016 \\
\hline Arterial hypertension-no. (\%) & $2,836(91.3)$ & $1,242(84.8)$ & $<0.001$ \\
\hline Current smoker-no. (\%) & $1,401(45.1)$ & $623(32.0)$ & 0.105 \\
\hline Hypercholesterolemia-no. (\%) & $2,754(88.7)$ & $891(60.9)$ & $<0.001$ \\
\hline Stable angina-no. $(\%)$ & $2,671(86.0)$ & $1,197(81.8)$ & $<0.001$ \\
\hline Unstable angina- $(\%)$ & $391(12.6)$ & $211(14.4)$ & 0.088 \\
\hline Number of diseased coronary arteries & & & $<0.001$ \\
\hline One vessel-no. (\%) & $447(14.4)$ & $464(31.7)$ & \\
\hline Two vessels-no. $(\%)$ & $856(27.6)$ & $535(29.7)$ & \\
\hline Three vessels-no. (\%) & $1,803(58.0)$ & $565(38.6)$ & \\
\hline Prior myocardial infarction-no. $(\%)$ & $1,206(38.8)$ & $217(14.8)$ & $<0.001$ \\
\hline Prior aortocoronary bypass surgery - no. $(\%)$ & $463(14.9)$ & $71(4.8)$ & $<0.001$ \\
\hline Body mass index $\left(\mathrm{kg} / \mathrm{m}^{2}\right)$ & $27.6 \pm 4.2$ & $27.6 \pm 4.0$ & 0.813 \\
\hline Serum creatinine $(\mathrm{mg} / \mathrm{dl})$ & $1.0 \pm 0.3$ & $0.9 \pm 0.2$ & $<0.001$ \\
\hline $\begin{array}{l}\text { Serum low-density lipoprotein cholestero } \\
(\mathrm{mg} / \mathrm{dl})\end{array}$ & $103.7 \pm 37.1$ & $131.2 \pm 41.7$ & $<0.001$ \\
\hline
\end{tabular}


Table 2 Lesion and procedural characteristics

Data are mean \pm SD or number of lesions (with percents in parentheses)

Table 3 Main concomitant drug therapy at admission

Data are number of patients (with percents in parentheses)

\begin{tabular}{|c|c|c|c|}
\hline Characteristic & On statins $(n=5,255)$ & Not on statins $(n=2,500)$ & $P$ value \\
\hline Target vessel & & & $<0.001$ \\
\hline Left main coronary artery-no. $(\%)$ & $226(4.3)$ & $67(2.7)$ & \\
\hline LAD coronary artery-no. $(\%)$ & $1,977(37.6)$ & $1,098(43.9)$ & \\
\hline Left circumflex coronary artery-no. $(\%)$ & $1,347(25.6)$ & $643(25.7)$ & \\
\hline Right coronary artery-no. $(\%)$ & $1,579(30.1)$ & $679(27.2)$ & \\
\hline Venous bypass graft-no. (\%) & $126(2.4)$ & $13(0.5)$ & \\
\hline Complex (B2/C) lesions no. (\%) & $3,604(68.6)$ & $1,642(65.7)$ & 0.010 \\
\hline Chronic occlusions no. (\%) & $350(6.7)$ & $184(7.4)$ & 0.255 \\
\hline Lesion length (mm) & $14.36 \pm 8.68$ & $14.21 \pm 9.11$ & 0.480 \\
\hline Vessel size $(\mathrm{mm})$ & $2.84 \pm 0.55$ & $2.83 \pm 0.55$ & 0.388 \\
\hline Diameter stenosis prior to procedure $(\%)$ & $62.4 \pm 15.4$ & $64.3 \pm 14.8$ & $<0.001$ \\
\hline Maximal balloon pressure (atm) & $16[13 ; 18]$ & $14[12 ; 17]$ & $<0.001$ \\
\hline Balloon-to vessel ratio & $1.10 \pm 0.1$ & $1.09 \pm 0.1$ & 0.028 \\
\hline \multicolumn{4}{|l|}{ Type of intervention } \\
\hline Drug-eluting stent no. (\%) & $4,570(87.0)$ & $2,229(89.2)$ & $<0.001$ \\
\hline Bare-metal stent no. (\%) & $291(5.5)$ & $145(5.8)$ & \\
\hline Balloon angioplasty no. (\%) & $394(7.5)$ & $126(5.0)$ & \\
\hline Length of stented segment (mm) & $23.0 \pm 11.1$ & $22.4 \pm 10.8$ & 0.034 \\
\hline Diameter stenosis after procedure $(\%)$ & $12.5 \pm 10.4$ & $12.2 \pm 11.1$ & 0.305 \\
\hline
\end{tabular}

\begin{tabular}{lllr}
\hline Characteristic & On statins $(n=3,106)$ & Not on statins $(n=1,464)$ & $P$ value \\
\hline Aspirin & $2,815(90.6)$ & $864(59.0)$ & $<0.001$ \\
Clopidogrel & $1,494(48.1)$ & $226(15.4)$ & $<0.001$ \\
Angiotensin-converting enzyme inhibitor & $1,986(63.9)$ & $546(37.3)$ & $<0.001$ \\
$\beta$-blocker & $2,598(83.6)$ & $736(50.3)$ & $<0.001$ \\
\hline
\end{tabular}

Table 4 Primary quadruple endpoint, triple endpoint, and their components

\begin{tabular}{lccc}
\hline Characteristic & $\begin{array}{l}\text { On statins } \\
(n=3,106)\end{array}$ & $\begin{array}{l}\text { Not on statins } \\
(n=1,464)\end{array}$ & $\begin{array}{c}P \text { value } \\
\text { interaction }\end{array}$ \\
\hline $\begin{array}{l}\text { Composite of death, myocardial infarction, urgent target vessel } \\
\text { revascularization, or major bleeding }\end{array}$ & $246(7.9)$ & $143(9.8)$ & 0.036 \\
$\begin{array}{l}\text { Composite of death, myocardial infarction or urgent target } \\
\text { vessel revascularization }\end{array}$ & $164(5.3)$ & $85(5.8)$ & 0.05 \\
Death & $5(0.2)$ & $2(0.1)$ & 0.046 \\
Myocardial infarction & $156(5.0)$ & $82(5.6)$ & 0.411 \\
Urgent target vessel revascularization & $21(0.7)$ & $15(1.0)$ & 0.024 \\
Major bleeding & $107(3.4)$ & $67(4.6)$ & 0.028 \\
\hline
\end{tabular}

Data are number of patients (with percents in parentheses)

incidence of myocardial infarction (4.9 vs. 5.2\%, $P=0.730)$ compared with UFH. On the other hand, among patients not taking statins, there was a significant difference in the incidence of myocardial infarction favoring UFH (4.1 vs. $7.1 \%, P=0.013$ ) which led to a significant differences in the triple composite of ischemic complications (death, myocardial infarction or urgent target vessel revascularization) favoring UFH therapy (4.2 vs. $7.4 \%$ in the bivalirudin group, $P=0.010$ ). In the nonstatin group, major bleeding remained numerically lower with bivalirudin than with UFH (4.0 vs. $5.2 \%, P=0.250$ ).

The dependence of the statin-antithrombotic agent interaction regarding the incidence of myocardial infarction was tested in the multivariable model investigating the 
Table 5 Primary quadruple endpoint, secondary triple endpoint and their components

\begin{tabular}{|c|c|c|c|c|c|c|}
\hline & \multicolumn{2}{|c|}{ On statin therapy $(n=3,106)$} & \multirow[t]{2}{*}{$P$ value } & \multicolumn{2}{|c|}{$\begin{array}{l}\text { Not on statin therapy } \\
(n=1,464)\end{array}$} & \multirow[t]{2}{*}{$P$ value } \\
\hline & $\begin{array}{l}\text { Bivalirudin } \\
(n=1,555)\end{array}$ & $\begin{array}{l}\text { Heparin } \\
(n=1,551)\end{array}$ & & $\begin{array}{l}\text { Bivalirudin } \\
(n=734)\end{array}$ & $\begin{array}{l}\text { Heparin } \\
(n=730)\end{array}$ & \\
\hline $\begin{array}{l}\text { Composite of death, myocardial infarction, urgent } \\
\text { target vessel revascularization or major bleeding }\end{array}$ & $111(7.1)$ & $135(8.7)$ & 0.106 & $79(10.8)$ & $64(8.8)$ & 0.198 \\
\hline $\begin{array}{l}\text { Composite of death, myocardial infarction } \\
\text { or urgent target vessel revascularization }\end{array}$ & $80(5.1)$ & $84(5.4)$ & 0.735 & $54(7.4)$ & $31(4.2)$ & 0.010 \\
\hline Death & $1(0.06)$ & $4(0.26)$ & 0.178 & $2(0.3)$ & $0(0.0)$ & 0.158 \\
\hline Myocardial infarction & $76(4.9)$ & $80(5.2)$ & 0.730 & $52(7.1)$ & $30(4.1)$ & 0.013 \\
\hline Urgent target vessel revascularization & $10(0.6)$ & $11(0.7)$ & 0.822 & $9(1.2)$ & $6(0.8)$ & 0.442 \\
\hline Major bleeding & $41(2.6)$ & $66(4.3)$ & 0.013 & $29(4.0)$ & $38(5.2)$ & 0.250 \\
\hline
\end{tabular}

Data are number of patients (with percents in parentheses)

independent correlates of myocardial infarction (see "Methods" for the variables entered into the model). The model showed that the independent predictors of increased risk of myocardial infarction at 30 days were: absence of statin use at randomization $(P=0.006)$, use of bivalirudin $(P=0.015)$, female sex $(P=0.010)$, unstable angina $(P=0.023)$, multivessel disease $(P<0.001)$. In the multivariable model, there was a significant interaction between statin therapy and type of antithrombotic agent $(P=0.026)$ in the sense that best outcomes with bivalirudin were achieved in patients on statin therapy before the procedure. These $P$ values continued to show significance even after adjustment for concomitant drug therapy recorded at admission.

\section{Discussion}

We describe on the basis of a post-hoc analysis a clinically relevant influence of statins on the safety and efficacy of antithrombotic therapy during PCI. Since these results are based on a post-hoc analysis they must be taken with care and regarded as hypothesis generating. These results indicate that despite having a more adverse cardiovascular risk profile, patients on statin therapy at the time of PCI had better 30-day clinical outcomes than patients who were not on statins. However, the principal finding of this analysis was that statin therapy at the time of PCI was associated with a significantly better outcome among patients assigned to bivalirudin, primarily by reducing the frequency of procedural MI. Furthermore, the known ability of bivalirudin to reduce in-hospital major bleeding seemed to be accentuated among patients taking statins. Since statin therapy is pivotal in the pharmacological treatment of patients with cardiovascular diseases, and essentially all patients with coronary disease (and certainly those with disease significant enough to require a PCI) ought to be on a statin, and the use of antithrombotic therapy is mandatory during PCI, the findings of the present study may be of particular clinical importance.

Bivalirudin is a relatively new direct thrombin inhibitor which has been investigated for potential pharmacodynamic interactions with other antithrombotic and antiplatelet drugs as part of its preclinical evaluation studies. It was shown that bivalirudin does not have a pharmacodynamic interaction with ticlopidine, glycoprotein IIb/IIIa inhibitors, low molecular weight heparins or UFH [16]. In addition, bivalirudin has been administered safely with aspirin and clopidogrel in clinical trials [16]. Bivalirudin is not metabolized by the cytochrome P-450 enzymatic system and does not bind to plasma proteins other than thrombin. Therefore, its potential for drug-drug interactions is believed to be low [17].

Growing evidence is available that the treatment with statins can lead to a significant downregulation of the coagulation cascade, most probably as a result of decreased tissue factor expression, which leads to reduced thrombin generation, suggesting that these drugs might act as "weak anticoagulants" [18, 19]. On the other hand, atorvastatin resulted in a significant decrease in plasma concentrations of antithrombin III by decreasing the biosynthetic ability of hepatocytes [20]. Unlike bivalirudin, which is a direct thrombin inhibitor, UFH is an indirect thrombin inhibitor whose mechanism of action requires antithrombin III. Deficiency in antithrombin III is known to be associated with reduced efficacy of heparin [21].

In light of these results, future studies or retrospective analyses of previous studies comparing UFH and bivalirudin during PCI ought to be performed to see if this finding can be confirmed. Since the majority of acute myocardial infarctions occur as a first manifestation of coronary artery disease, it is interesting to speculate 
whether a small number of patients in the Harmonizing Outcomes with Revascularization and Stents in Acute Myocardial Infarction (HORIZONS-AMI) trial were on statins at time of PCI, which might explain the high rate of acute stent thrombosis in the bivalirudin arm in the first $24 \mathrm{~h}$ of this trial [4].

Bivalirudin, in contrast to UFH and low molecular weight heparin, is active against fibrin-bound thrombin by a bivalent and reversible bond. It does not activate platelets, does not bind to plasma proteins, does not cause heparin-induced thrombocytopenia, and has linear pharmacokinetics with a short half-life of $25 \mathrm{~min}$ [16]. These pharmacologic properties suggest that bivalirudin has a wide therapeutic range, which should translate into both less thrombotic events and less bleeding compared with unfractionated and low molecular weight heparins. Clinical trials, however, failed to demonstrate a reduction in ischemic complications with bivalirudin compared with UFH. The novel finding of this analysis is that bivalirudin therapy was associated with better outcomes in terms of ischemic and bleeding complications among patients already on statins at the time of PCI. We cannot know for sure that this finding on post-hoc analysis is real, let alone confirm the exact mechanism of this influence. In this analysis, two-thirds of patients were on statins at time of enrollment. The percentage of patients undergoing PCI who are on statins may increase in the future due to recent findings suggesting that even healthy individuals with low LDL cholesterol and elevated C-reactive protein experience a marked reduction in cardiovascular morbidity and mortality when treated with $20 \mathrm{mg}$ rosuvastatin compared to placebo [22].

The other relevant finding of this study is the confirmation of the previously described positive effect of preprocedural statin therapy on peri-procedural adverse events and, in particular, procedural myocardial infarction [7-10]. Lack of statin therapy at the time of PCI was an independent risk predictor for development of myocardial infarction at 30 days in our analysis as well.

In a previous analysis from the ISAR-REACT 3 trial, we showed that bivalirudin and unfractionated heparin had different effects on the risk of bleeding and myocardial infarction across various subsets of patients [23]. Neither bivalirudin nor heparin showed any specific advantage in high-risk subsets for bleeding or myocardial infarction, respectively. Subsets of patients who showed the greatest reduction in the risk of bleeding with bivalirudin showed a greater increase in the risk of myocardial infarction [23].

The present study was a post-hoc analysis of the ISARREACT 3 trial and, therefore, it is subject to limitations inherent to this type of studies. Findings of subgroup analysis should be interpreted with caution because of the potential for erroneous findings due to multiple testing. We did not document the duration, type nor dose of preprocedural statin therapy, which precludes any conclusions in this regard. Nonetheless, the present analysis describes for the first time an apparent interaction with statins which enables bivalirudin to reduce both bleeding and ischemic complications after PCI. There were no specific tests done to measure the antithrombotic action of the drugs examined. This interaction should be examined in other studies.

In conclusion, there appears to be an interaction between statin therapy before PCI and the antithrombotic therapy (bivalirudin) during the procedure. Statins also appeared to have had a favorable effect on the incidence of post-procedural myocardial infarction, which would justify their initiation before PCI regardless of which antithrombotic is used, if possible.

\section{References}

1. Ndrepepa G, Berger PB, Mehilli J, Seyfarth M, Neumann FJ, Schömig A, Kastrati A (2008) Periprocedural bleeding and 1-year outcome after percutaneous coronary interventions: appropriateness of including bleeding as a component of a quadruple end point. J Am Coll Cardiol 51:690-697

2. Lincoff AM, Bittl JA, Harrington RA et al (2003) Bivalirudin and provisional glycoprotein IIb/IIIa blockade compared with heparin and planned glycoprotein IIb/IIIa blockade during percutaneous coronary intervention: REPLACE-2 randomized trial. JAMA 289:853-863

3. Stone GW, White HD, Ohman EM, Bertrand ME, Lincoff AM, McLaurin BT, Cox DA, Pocock SJ, Ware JH, Feit F, Colombo A, Manoukian SV, Lansky AJ, Mehran R, Moses JW (2007) Bivalirudin in patients with acute coronary syndromes undergoing percutaneous coronary intervention: a subgroup analysis from the Acute Catheterization and Urgent Intervention Triage strategy (ACUITY) trial. Lancet 369:907-919

4. Stone GW, Witzenbichler B, Guagliumi G, Peruga JZ, Brodie BR, Dudek D, Kornowski R, Hartmann F, Gersh BJ, Pocock SJ, Dangas G, Wong SC, Kirtane AJ, Parise H, Mehran R (2008) Bivalirudin during primary PCI in acute myocardial infarction. N Engl J Med 358:2218-2230

5. Kastrati A, Neumann FJ, Mehilli J, Byrne RA, Iijima R, Büttner HJ, Khattab AA, Schulz S, Blankenship JC, Pache J, Minners J, Seyfarth M, Graf I, Skelding KA, Drischinger J, Richardt G, Berger PB, Schömig A (2008) ISAR-REACT 3 Trial investigators. Bivalirudin versus unfractionated heparin during percutaneous coronary intervention for angina pectoris. N Engl J Med 359:688-696

6. Stone GW, Ware JH, Bertrand ME, Lincoff AM, Moses JW, Ohman EM, White HD, Feit F, Colombo A, McLaurin BT, Cox DA, Manoukian SV, Fahy M, Clayton TC, Mehran R, Pocock SJ (2007) Antithrombotic strategies in patients with acute coronary syndromes undergoing early invasive management: one-year results from the ACUITY trial. JAMA 298:2497-2506

7. Ebrahimi R, Saleh J, Toggart E, Shah AP, Azmoon S, Babaei H, Lee J, Smith R, Movahed R, Rubin S (2008) Effect of preprocedural statin use on procedural myocardial infarction and major adverse cardiac adverse events in percutaneous coronary intervention: a meta-analysis. J Invasive Cardiol 20:292-295

8. Mood GR, Bavry AA, Roukoz H, Bhatt DL (2007) Meta-analysis of the role of statin therapy in reducing myocardial infarction 
following elective percutaneous coronary intervention. Am J Cardiol 100:919-923

9. Di Sciascio G, Patti G, Pasceri V, Gaspardone A, Colonna G, Montinaro A (2009) Efficacy of atorvastatin reload in patients on chronic statin therapy undergoing percutaneous coronary intervention: results of the ARMYDA-RECAPTURE (Atorvastatin for Reduction of Myocardial Damage During Angioplasty) Randomized Trial. J Am Coll Cardiol 54:558-565

10. Zhao JL, Yang YJ, Pei WD, Sun YH, Chen JL, Gao RL (2008) Effect of statin therapy on reperfusion arrhythmia in patients who underwent successful primary angioplasty. Clin Res Cardiol 97:147-151

11. Levine GN, Keaney JF Jr, Vita JA (1995) Cholesterol reduction in cardiovascular disease. Clinical benefits and possible mechanisms. N Engl J Med 332:512-521

12. Dangas G, Smith DA, Unger AH, Shao JH, Meraj P, Fier C, Cohen AM, Fallon JT, Badimon JJ, Ambrose JA (2000) Pravastatin: an antithrombotic effect independent of the cholesterollowering effect. Thromb Haemost 83:688-692

13. Wolfrum S, Grimm M, Heidbreder M, Dendorfer A, Katus HA, Liao JK, Richardt G (2003) Acute reduction of myocardial infarct size by a hydroxymethyl glutaryl coenzyme A reductase inhibitor is mediated by endothelial nitric oxide synthase. J Cardiovasc Pharmacol 41:474-480

14. Wolfrum S, Dendorfer A, Schutt M, Weidtmann B, Heep A, Tempel K, Klein HH, Dominiak P, Richardt G (2004) Simvastatin acutely reduces myocardial reperfusion injury in vivo by activating the phosphatidylinositide 3-kinase/Akt pathway. J Cardiovasc Pharmacol 44:348-355

15. van der Harst $P$, Böhm M, van Gilst WH, van Veldhuisen DJ (2008) The case for statin therapy in chronic heart failure. Clin Res Cardiol 97:139-146

16. Caron MF, McKendall GR (2003) Bivalirudin in percutaneous coronary intervention. Am J Health Syst Pharm 60:1841-1849
17. Ramana RK (2008) Lewis BE: percutaneous coronary intervention in patients with acute coronary syndrome: focus on bivalirudin. Vasc Health Risk Manag 4:493-505

18. Undas A, Brummel-Ziedins KE, Mann KG (2005) Statins and blood coagulation. Arterioscler Thromb Vasc Biol 25:287-294

19. Undas A, Celinska-Lowenhoff M, Brummel-Ziedins KE, Brozek J, Szczeklik A, Mann KG (2005) Simvastatin given for 3 days can inhibit thrombin generation and activation of factor $\mathrm{V}$ and enhance factor $\mathrm{Va}$ inactivation in hypercholesterolemic patients. Arterioscler Thromb Vasc Biol 25:1524-1525

20. Tousoulis D, Antoniades C, Bosinakou E, Kotsopoulou M, Tsioufis C, Tentolouris C, Trikas A, Pitsavos C, Stefanadis C (2005) Effects of atorvastatin on reactive hyperaemia and the thrombosis-fibrinolysis system in patients with heart failure. Heart 91:27-31

21. Avidan MS, Levy JH, van Aken H, Feneck RO, Latimer RD, Ott E, Martin E, Birnbaum DE, Bonfiglio LJ, Kajdasz DK, Despotis GJ (2005) Recombinant human antithrombin III restores heparin responsiveness and decreases activation of coagulation in heparin-resistant patients during cardiopulmonary bypass. J Thorac Cardiovasc Surg 130:107-113

22. Ridker PM, Danielson E, Fonseca FA, Genest J, Gotto AM Jr, Kastelein JJ, Koenig W, Libby P, Lorenzatti AJ, MacFadyen JG, Nordestgaard BG, Shepherd J, Willerson JT, Glynn RJ (2008) JUPITER Study Group. Rosuvastatin to prevent vascular events in men and women with elevated C-reactive protein. N Engl J Med 359:2195-2207

23. Iijima R, Ndrepepa G, Mehilli J, Byrne RA, Schulz S, Neumann FJ, Richardt G, Berger PB, Schömig A, Kastrati A (2009) Profile of bleeding and ischemic complications with bivalirudin and unfractionated heparin after percutaneous coronary intervention. Eur Heart J 30:290-296 